Running head: SYNTACTIC SKILLS IN CHINESE

Syntactic Skills in Sentence Reading Comprehension among Chinese Elementary School Children

${ }^{1}$ Chik PPM, ${ }^{1} \mathrm{Ho} \mathrm{CSH},{ }^{1}$ Yeung PS, ${ }^{2}$ Chan DWO, ${ }^{3}$ Chung KKH, ${ }^{4}$ Luan H, ${ }^{5}$ Lo LY, \& ${ }^{1}$ Lau WSY

\author{
${ }^{1}$ The University of Hong Kong \\ ${ }^{2}$ The Chinese University of Hong Kong \\ ${ }^{3}$ Hong Kong Institute of Education \\ ${ }^{4}$ Hong Kong Baptist University \\ ${ }^{5}$ HongKong Shue Yan University
}




\begin{abstract}
The present study examined the role of syntactic skills for reading comprehension in Chinese. Two hundred and seventy-two Chinese children were tested on their phonological processing, orthographic, morphological, syntactic, and literacy skills at Grades 1 and 2. Hierarchical multiple regression results showed that syntactic skills, in terms of word order, connective usage, and knowledge of morphosyntactic structure (measured by an oral cloze task) in Grade 1, significantly predicted sentence reading comprehension in Grade 2 after controlling for the children's age, IQ, and word level reading-related cognitive skills in Grade 1, and word reading in Grade 2. As in alphabetic languages, syntactic skills are essential for reading comprehension in Chinese. The unique roles of individual syntactic skills for understanding sentences in Chinese are discussed.
\end{abstract}

(123 words) 


\section{Syntactic Skills in Sentence Reading Comprehension among Chinese Elementary School Children}

\section{Introduction}

A rich literature has been accumulated to support the significance of word-level processing on reading over the past few decades. In the alphabetic writing systems, the intimate relationship between the development of phonological processing skills and the acquisition of beginning reading skills has long been established (Bradley \& Bryant, 1985; Liberman, Shankweiler, \& Liberman, 1989; Treiman, 1991; Tunmer \& Nesdale, 1985). Orthographic skills which is closely related with phonological knowledge in alphabetic languages (Cunningham \& Stanovich, 1991; Juel, L., \& Gough, 1986; Olson, Wise, Conners, \& Rack, 1989) and morphological skills in English, in particular (Carlisle, 1988; Deacon \& Kirby, 2004; Fowler \& Liberman, 1995; Nunes, Bryant, \& Bindman, 1997) were also shown to have independent contribution to reading acquisition.

A slightly different picture is noted in Chinese which has a distinctive orthography from the alphabetic ones. Recent studies on Chinese developmental dyslexia have suggested that phonological awareness is less important in learning to read Chinese than in learning to read English (Ho, Chan, Lee, Tsang, \& Luan, 2004; Ho, Chan, \& Tsang, 2002; Shu, McBride-Chang, Wu, \& Liu, 2006). Rather, it has been repeatedly demonstrated that orthographic skills or knowledge as measured by radical knowledge in Chinese reading (Ho, Ng, \& Ng, 2003; Shu, Anderson, \& Wu, 2000; Yang \& Peng, 1997) and that of morphological skills, especially in terms of homophone awareness and morpheme construction (Ku \& Anderson, 2003; Li, Anderson, Nagy, \& Zhang, 
2002; McBride-Chang \& Ho, 2005; Shu, Anderson, \& Zhang, 1995; Shu, McBride-Chang et al., 2006) have a significant role to play in learning to read Chinese.

Comparatively speaking, fewer attempts have been made to explore the association of textlevel reading with related cognitive factors in alphabetic languages and even less in nonalphabetic writing systems, like Chinese. In general, the findings support an independent role of syntactic processing skills or awareness in reading at the text level.

\section{Syntactic Processing and Text-Level Reading in Alphabetic Languages}

Syntactic skills represent the ability to recognize and use the grammatical structures in a language (Gombert, 1992, p. 32). The development of such skills in alphabetic languages, as measured by age-related changes in the ability to judge and revise unacceptable sentences, shows a rapid change in middle childhood (Hakes; Tummer, Herriman, \& Nesdale, 1988) and a gradual shift from looking for semantic to syntactic properties in a sentence (Hakes; Van Kleeck, 1982).

One theoretical issue that concerns the role of syntactic awareness in reading in alphabetic languages was its contribution to reading as compared with phonological processing skills. Studies undertaken in the 80 s and early 90 s, which examined the relationships between readingrelated cognitive factors and reading ability, tended to support the phonological limitation processing hypothesis (Shankweiler, Crain, \& Brady, 1992) in which deficient phonological processing skills was believed to be the primary determinant of reading disability. Gottardo, Stanovich and Siegel (1996), for instance, examined the predictive influence of phonological sensitivity, working memory and syntactic processing on reading performance in a group of normally-achieving third graders. They found that phonological sensitivity (reflected in syllable 
and phoneme deletion tasks) remained a strong predictor for reading comprehension after the variance of working memory and syntactic processing had been controlled for. Syntactic processing skills, however, failed to account for significant independent variance in any of the reading ability measures after controlling for phonological sensitivity and working memory. Similar findings were observed in other studies conducted at the time (Rack, Hulme, Snowling, \& Wightman, 1994; Share \& Stanovich, 1995; Stanovich, 1988, 1992).

More recent works in this area however pose a challenge to the phonological limitation hypothesis. It was observed on the one hand that poor readers or children with reading disabilities exhibited a significant lag in the development of grammatical sensitivity or syntactic competence, besides a greater deficit in phonological processing skills and/or a poorer short-term memory (Bentin, Deutsch, \& Liberman, 1990; Siegel \& Ryan, 1988; Tummer, Nesdale, \& Wright, 1987). On the other hand, syntactic awareness, as measured by a variety of syntactic tasks, including oral cloze, word order or judgement/error correction task, remained a strong predictor for children's performance on reading comprehension (Deutsch \& Bentin, 1996; Gombert, 1992; Muter, Hulme, Snowling, \& Stevenson, 2004; Nation \& Snowling, 2000; Plaza, 2001; Plaza \& Cohen, 2003, 2004) after controlling for the variance of phonological awareness.

\section{Syntactic Processing and Text-level Reading in Chinese}

The literature about syntactic processing and reading comprehension is relatively thinner in Chinese. Yet, the independent role of syntactic skills in text-level reading in the language is more consistently supported in the research studies, than that in the alphabetic languages. The study by Chen, Lau, and Yung (1993) showed that the strong predictive power of phonological 
recoding skill in Chinese reading deteriorated chronologically after Grade 3. They also found that the role of semantic analysis skills began to be significant from Grade 3 and that of syntactic skills (in terms of word insertion and detection of grammatical error in a sentence) in reading remained important from Grade 1 up to Grade 6. Similar findings were observed in So and Siegel's study (1997) which investigated the relationships among Chinese word reading, phonological awareness, semantic skills, and syntactic skill (measured by an oral cloze task) in Grade 1 to Grade 4 Chinese children in Hong Kong. The results of hierarchical regression analyses showed that both phonological and syntactic skills were strong predictors of children's word reading performance in the early grades, whereas semantic skills became predictive for reading in grade 4. Despite somewhat different tasks being used in the two studies, their results provide positive indication that syntactic skills appear to be at least as important as phonological ones, whereas semantic skills seem to begin to take significance with the growth of reading skills in the early stage of literacy development.

The developmental changes of syntactic skills in Chinese appear to be similar to those observed in the alphabetic languages. In 1992, Song studied the development of syntactic awareness in 4- to 8-year-old Mandarin-speaking children by means of a sentence judgement task that encompassed word order changes, morphological violations (agreement in using nouns, verbs, and adverbials in sentences) and missing parts of speech. In Song's study, the 4-year-old group displayed scarcely sentence judgement ability and significant increases in such ability were observed between the age of 4 and that of 5-7, and between the ages of 5-7 and that of 8 . It was also found that younger children between the ages of 4-7 tended to provide reasons focusing on semantic meaning than syntactic rules and structures in making the judgement. Such a 
developmental pattern is in line with what has been revealed in the western studies using similar tasks, as mentioned earlier.

Consistent with Song's study, Tsang and Stokes (2001) also found a significant age effect in the performance on judgement and revision tasks among four groups of Cantonese-speaking children and adults. The seven years old in their study were found to be able to attain adult-like performance on the tasks. However, unlike the findings of Pratt, Tunmer, and Bowey (1984) which revealed a better performance of English-speaking children in revisions with morphological violations than that with word order changes, children in Tsang and Stokes' study scored higher on word order than morphological revisions. This may suggest a possible influence of language-specific characteristics on children's syntactic awareness. An overview of the syntactic characteristics of Chinese may help us better understand the apparent discrepancy in the role of syntactic skills in predicting reading in Chinese and in alphabetic languages respectively.

\section{Characteristics of Chinese Syntax}

Chinese is a morpho-syllabic writing system (DeFrancis, 1984), signifying a characterbased orthography and a grapheme-morpheme correspondence in comprehension. Unlike alphabetic languages such as English, there is no inflectional system, such as subject-verb agreement and case marking in Chinese (Li \& Thompson, 1981). Therefore, instead of morphological transformations in alphabetic languages, morphosyntax, or word compounding is used to show tense, number, and degree. For example, Chinese has in general no plural form of nouns. Characters like 狗, 椅, 菜 can denote either singular or plural form - dog/dogs, chair/ 
chairs and vegetable/vegetables. They may also be joint with quantifiers, such as 一群 (a group), 一些 (some), 許多 (many) to indicate their plurality. Anaphoric expressions, such as 我 (I), 你 (you) and 他 (he) are however exceptional and usually combine with a post-nominal plural marker 們 to show their plural forms of we (我們), you (你們) and they (他們). There is also no transformation of verbs for tense in Chinese. Instead, a category of words, the function, or empty words (similar to prepositions in English), are used in combination with the main verbs to show different tenses in Chinese, for instance, listened being represented by 聽 (listen) 了 (-ed, past action) and listening by 聽 (listen) 着 (-ing, continuous action). Since there is a lack of inflectional system in Chinese, reading to comprehend Chinese sentences and texts meant for the reader to be able to solicit syntactic information from the given linguistic constituents and their semantic relationships (Chao, 1968; Li \& Thompson, 1981).

The strong emphasis on the syntactic and semantic relationships between linguistic constituents in reading at the text level also manifests in a bigger flexibility of word order of sentences in Chinese than in the alphabetic languages. Specifically, Chinese is a topic-prominent language (Chao, 1968; Li \& Thompson, 1981). Once a topic word or phrase has been established, it can be extended across succeeding sentences. Therefore, although the canonical word order in written Chinese is Subject-Verb-Object (SVO), as that in English, the subject noun/phrase can be omitted given that a topic has been established among a group of sentences, for example: 小美我 見過了。很漂亮。也很能幹。 (Siu Mei [the topic] I have just met. [The topic, i.e., She is] Very beautiful. [The topic, i.e., She is] Very capable as well). When the topic happens to be the object noun/phrase, two specific types of Object-Subject-Verb (OSV) word order - "BA [把] 
sentence structure” and “BEI [被] sentence structure” - are used, for example: 我弄骿了媽媽新 買的裙子 (I smeared mother's new dress) is a SVO sentence and can be converted to BA and BEI sentence structures 我 把 媽媽新買的裙子弄骿了 (I BA mother's new dress smeared) and 媽媽新買的裙子 被我弄骿了(Mother’s new dress BEI I smeared), where 媽媽新買的裙子 (Mother's new dress) becomes the topic. Given these specific features of Chinese sentence structures, some Chinese linguistics argue that word order is one of the essential elements for readers to comprehend texts in the language (Chao, 1968; Li \& Thompson, 1981; Wang, 1955). Apart from flexible word order, the impoverishment of morphosyntactic transformation in Chinese also makes determination of the use of word class difficult when no context is provided. For instance, 祝福 could be a verb (to bless) or a noun (blessings) depending on the context (e.g., 新年時, 我們互相 祝福 In the New Year, we bless each other; 生日那天, 她收 到了許多 祝福 On her birthday, she has received a lot of blessings.). Therefore, the understanding of basic morphosyntactic structure of and the relative use of word class in a sentence should also be an essential syntactic skill for text-level reading in Chinese. This skill has often been measured by an oral cloze task (e.g., So \& Siegel, 1997).

The third potentially important syntactic skill concerns the use of connectives, a category of cohesive devices (Halliday \& Hasan, 1976) which take up specific positions and linguistic functions in sentences. As noted by Liu (1999), the usage of connectives is distinctively extensive in Chinese writings and may thus constitute another important component for reading comprehension in Chinese. 
As mentioned, current literature focuses on word-level reading related factors and their contributions to reading comprehension in formal written Chinese. The role of syntactic skills, a text-level factor related to reading, has yet to be established. Therefore, the present study aimed at examining the role of syntactic skills in Chinese and how it predicted longitudinally reading comprehension in Chinese Cantonese-speaking children over that of phonological processing, orthographic, and morphological skills. In particular, the present study aimed to look into the relative contributions of three syntactic components - basic morphosyntactic structure, word order, and connective usage to Chinese reading comprehension.

\section{Method}

\section{Participants}

Participants of this study were 272 Chinese first-grade students whose mother tongue was Cantonese. There were 139 girls and 133 boys recruited from two primary schools in Hong Kong with normal intelligence (mean $I Q=110$ ). The children were tested on general reasoning ability, phonological processing skills, orthographic skills, morphological skills, and syntactic skills when they were in Grade 1, and later on two reading measures when they were in Grade 2 (mean age $=8$ years $)$.

\section{Measures}

Two measures of the present study, namely rhyme detection and word repetition, were developed based on the corresponding subtests of the Hong Kong Test of Specific Learning Difficulties in Reading and Writing (HKT-SpLD) (Ho, Chan, Tsang, \& Lee, 2000). The HKTSpLD is a standardized test developed to assess Hong Kong primary school children suspected to 
have dyslexia. There are 12 subtests in the HKT-SpLD, which are grouped into four areas:

literacy, rapid naming, phonological skills, and orthographic skills. The reliability coefficients of the Rhyme Detection and the Word Repetition subtests were .7 and .82 respectively. The construct, convergent, and discriminant validities of the Test are also reported to be good. Local norms are available from 6 years 1 month to 10 years 6 months.

Several local Chinese language teachers of primary schools were consulted to improve the test items constructed for this study. For instance, they were asked what types of connectives were learned by Chinese first and second graders in Hong Kong. Several pilot studies were also conducted to ensure the suitability of all the measures developed in this study.

\section{General Reasoning Ability}

The participants' general reasoning ability was assessed by the Raven's standard progressive matrices. This is a standardized test for measuring nonverbal intelligence, including five sets of 12 items each. Each item consisted of a target matrix with a missing piece. Children were required to pick, from six to eight alternatives, the best part to complete the target matrix. The short form of the test, made up of the first three sets of the full form, was administered to participants of less than 8.5 years old in the present study. Scoring procedures were based on the local norm established by the Education Department of The Hong Kong Government in 1986. Phonological Processing Skills

Rhyme detection. This task was modeled after the design of the rhyme detection subtest of the HKT-SpLD (Ho, Chan, Tsang, \& Lee, 2000). While using the same test procedures, new items were developed for the participants in this study. In each trial, the children were presented with three Chinese syllables in Cantonese through a computer audio system, along with their 
corresponding pictures to ease their memory load. For example, in one item, the child heard /sam1/ (心 heart), /dou1/ (刀 knife), /bou1/ (煲 pot). The tone of the three syllables in each trial was the same, while the onsets of the three syllables were different. The two target syllables shared the same rhyme while the rhyme of the distractor syllables differed from the target syllables. Children were asked to identify the two syllables sharing the same rhyme in each trial by circling the corresponding pictures. There were 12 trials in this task and one mark was given for the correct answers in each trial. Two practice trials were given before the test.

Word repetition. A word repetition task was developed to measure the children's phonological memory. It was based on the design of the word repetition subtest of the HKTSpLD (Ho et al., 2000) with items being modified. Eight sequences of legal Cantonese syllables, ranging from 3 to 6 syllables long, were presented in order of ascending length (e.g., /bei1/, /hoil/, /jin1/). Syllables in each sequence were of identical tone but different in onsets and rhymes. The stimuli were recorded in mp3 files and presented through an mp3 player to the children. In each trial, the children were required to repeat orally the syllables heard in the presented order. Each sequence was only presented once. The answers were scored according to the accuracy of the pronunciation and the order of the syllables recalled. One mark was given to each accurately recalled syllable and another mark was given to each correct sequence of two syllables. There was one practice trial. The instructions and the practice trial were repeated until the child understood the task.

Rapid naming of numbers. This task was similar to the traditional rapid automatized naming tasks (Denckla \& Rudel, 1976). Five digits, namely 1, 2, 5, 6, and 8, were printed in a 5 x 8 matrix on an A4 size paper. Before the test, the children were asked to read out the five digits 
in the first line to make sure that they could name the digits correctly. The children were then instructed to name the digits in Cantonese from left to right and from top to bottom as quickly and accurately as possible. They were asked to name the list twice. The average latency across the two trials was computed to the nearest 1/100 second and this was the score for analyses.

\section{Orthographic Skills}

Pseudo-character meaning judgment. This task was adapted from Ho et al.'s (2003) study to measure the children's overall awareness of positions, functions, and semantic categories of different semantic radicals in written Chinese characters, using the same testing procedures but newly constructed items for the participants in this study. The reliability coefficient of this task was .95 and the score of this task correlated significantly with Chinese word reading in Ho et al.'s study. Each pseudo-character (e.g., 䘥) was composed of a semantic radical (e.g., 衸 “clothing") and a phonetic radical (e.g., 太/taai3/ ) in their legal positions but the combination was not a real Chinese character. Both lexical semantic radicals (i.e., the radicals were real characters when standalone, e.g., 皿 “container") and nonlexical semantic radicals (i.e., the radicals were noncharacters when standalone, e.g., 庐) were used to construct pseudo-characters. All pseudo-characters were checked against Kangxi Dictionary (Zhang, 1979) to ensure that they were not real characters. All the selected semantic radicals in the task were familiar to the children (Leung \& Lee, 2002) and most of them were taught explicitly in junior grades classrooms. In each item, the pseudo-character was placed next to four picture choices. The children were asked to circle the picture that might be semantically related to the meaning of the pseudo-character. The instruction was as follows:

\section{你睇下你本簿上面呢個得意字, 然後你估吓佢䁮意思同隔離呢四幅圖畫中邊一幅係}




\section{有關係? 試吓圈低你覺得有關嘅圖畫。}

[Take a look at the interesting character on the answer book and guess which of the four pictures by its side may be associated to its meaning. Circle the associated picture.] The children were tested how well they identified the semantic radical in a pseudo-character and selected a picture that related to the meaning of the character based on the meaning of its

semantic radical. For instance, meaning of the pseudo-character “䘥” was related to clothing as indicated by its semantic radical “齐”. Two practice items were presented before the 16 testing items. One mark was given for the correct answer to each question.

Phonological-relatedness judgment. This task was also adapted from Ho et al.'s (2003) study following their design principles with new items in measuring the children's awareness of the function of phonetic radicals. The reliability coefficient of this task was .77 and the score of this task correlated significantly with Chinese word reading in Ho et al.'s study. Pseudocharacters were constructed the same way as in the pseudo-character meaning judgment task. Phonetic radicals chosen must possess the same orthographic position as its ordinary form after becoming a part of a pseudo-character and they appeared in characters of Grade 1 to Grade 2 levels. In each item, the target pseudo-character was presented together with three choices, each of which being a real character. The children were asked to select the character among these three choices that might have the same or similar pronunciation as the target pseudo-character. The children were instructed as follows,

簿上面有一啲你未見過但係好得意噆字, 每個得意字下面都有三個字, 你依家試吓 估吓, 呢個得意字同下面呢三個字, 邊一個字旣讀音係相同或者相似, 然後圈住 佢。[There are some interesting characters which you might have never seen before. 
Underneath each interesting character, there are three characters. Your task is to guess which character shares the same or similar pronunciation with the interesting character and circle it.]

The three choice characters were: a character sharing the same semantic radical with the target pseudo-character, a character sharing the same phonetic radical (the correct answer), and a control character. For example, the pseudo-character技, the three choices were 肢 /zi1/ [limb] (the correct answer), 行/hang4/ [walk] (the character sharing the same semantic radical with the pseudo-character), and 神/san4/ [god] (the control character). Both target characters and distractors were matched in frequency. Three practice items were given at the beginning of the task. There were 18 testing items. One mark was given for identifying the character which had the same phonetic radical as the target pseudo-character of each item.

\section{Morphological Skills}

Homophone awareness. This task was used to assess children's ability to differentiate morphemes from homophones. In each item, three two-syllable Chinese words were orally presented to the children in Cantonese, and the words had an identical syllable at the same position. For example, the words /naam4 tsi3/ [男廁 male washroom], /naam4 dzai2/ [男仔 young boy], and /naam4 gik9/ [南極 South Pole] shared the same syllable /naam4/. The syllable of the first two words shared a meaning of male, whereas the syllable in the last word had a meaning of south. The children were asked to identify the two words that had a syllable sharing the same meaning and circle the numbers $(1,2$, or 3$)$ assigned to the words according to the presentation order. The written form of the words used, though not presented to the children, were unfamiliar to the children based on the frequencies in the Hong Kong Corpus of Primary 
School Chinese (Leung \& Lee, 2002). The position of the target syllables in the words and the order of correct answers were counterbalanced across items. There were two practice and 15 test items. One mark was given for each correctly answered item.

Morphological construction. This task was adapted from McBride-Chang and colleagues' (2003, 2005) study to measure the morphological structure awareness of the children. The same testing procedures were replicated, whereas new items were constructed for this study. In each item, an object or a concept was presented orally with a scenario in the form of a two- to threesentence story in Cantonese. The children were asked to construct new compound words for the presented objects or concepts based on previously learned morphemes. Each compound word included two to four characters. Each answer was given either 0, 1, or 2 points. For example, in one item, the child heard the following:

$$
\begin{aligned}
& \text { 有一種花 (/faa1/ [flower]) 係又大 (/daai6/ [big]) 又黃 (/wong4/ [yellow]) 魙, 我吔會叫 } \\
& \text { 佢做大黃花 (/daai6 wong4 faa1/ [Big-yellow-flower])。咁如果有一種花係又大又紫 }
\end{aligned}
$$

(/dzi2/ [purple]) 穊, 我吔會點叫佢呀? [If we call a flower that is big and yellow as Big-

$$
\text { yellow-flower, what should we call a flower that is big and purple?] }
$$

The correct answer for this item should be 大紫花/daai6 dzi2 faa1/ [Big-purple-flower] and was given 2 points. Answer that contained all major morphemes but did not conform completely to the morpheme construction rules (e.g., in this case, 紫大花/dzi2 daai6 faa1/ [Purple-big-flower]) was given 1 point. There were 2 practice and 12 test items for this task.

Morpheme comprehension. This task assessed the children's ability in understanding the meaning of novel compound words constructed with familiar morphemes in written Chinese. Characters chosen were familiar to the children in Grade 1 according to the Hong Kong Corpus 
of Primary School Chinese (Leung \& Lee, 2002). There were a total of 15 multiple-choice items. In each item, a pseudo-compound word or a real unfamiliar word was presented. All the words consisted of two or three morphemes and the meaning of the target words could be derived from the meaning of the component morphemes (e.g., 初 [beginning], 學 [to learn]). The children were then given three choices, each of which consisted of a phrase or a clause that contained the characters in the target words (e.g., 當初的學生 [student at the beginning], 初一去學習 [to learn on the first day of the month], and 初開始去學習 [beginning to learn]), and were asked to indicate which of the three given choices best explained the meaning of the target word (e.g., 初 學 [beginning to learn]). Target words and choice phrases were read to the children. Two practice items were completed before the 15 test items. One mark was given to each correctly answered item.

\section{Syntactic Skills}

It was difficult to develop absolutely clean syntactic measures that did not involve any literacy skills. To reduce any possible effect of reading, all items of the syntactic measures were read out to the children with or without print.

Oral Cloze. The oral cloze task adapted from So and Siegel's (1997) study was used to measure the participants' understanding of basic morphosyntactic structures in sentences. Nine audio-recorded sentences, each with one word missing, were presented to the child in the absence of print (see Examples 1 and 2 below). Three classes of missing words were used: nouns, verbs, and adjectives. Instructions and the trial item were repeated until the child understood how the task should be performed. Then, the test sentences were presented. The responses were audio-recorded and scored according to their syntactic and semantic appropriateness on a four- 
point scale according to three aspects: part of speech, semantic meaning, and conformity to Modern Standard Chinese.

Example 1: 我最喜歡的食物是 —。

My favourite food is

Example 2: _姐姐買了一條—裙子。

Sister bought a/an ___ dress.

Connective usage. This task measured the children's syntactic skill of using connectives at appropriate places of a complex sentence that consists of more than one clause in written Chinese. There were a total of 13 items. In eight of the items, the children were asked to insert one to three given identical connectives to appropriate places of a sentence (see Example 3 below).

Example 3: 有時 Sometimes $\left(^{\wedge}\right)$ 有時 Sometimes $\left(^{\wedge}\right)$ 小健^ 喜歡吃朱古力, ^喜歡吃雪糕。

Siu Kin ${ }^{\wedge}$ likes to eat chocolate, ${ }^{\wedge}$ likes to eat ice-cream.

Two pairs of unidentical connectives (i.e., with four choice words) were given in the other five items. In each of these items, the children were asked to first select two appropriate words that form a pair of connectives and then insert them in appropriate places of a sentence (see Example 4 below).

Example 4: $\quad$ 不但 Not only $\left({ }^{\wedge} 1\right)$ 而且 Also $\left({ }^{\wedge} 2\right)$ 然後 Then $\left({ }^{\wedge} 3\right)$ 首先 First $\left({ }^{\wedge} 4\right)$

孩子, 14 脫下你的鞋子, 13 走進遊樂場。 
Kids, $\wedge 4$ take off your shoes, $\wedge 3$ get into the playground.

All the selected connectives were common ones in Chinese textbooks and exercise books for Grade 1 students. To make sure that the children knew the words in each item, all the words were read aloud to them. Two practice items were provided at the beginning of each section. One point was given to each connective correctly inserted at the appropriate place of a sentence.

Word order. This task was used to measure the children's understanding of some basic sentence structure rules in written Chinese (e.g., canonical sentence types using subject-verbobject and subject-verb-verb structures, see Example 5 below; and special sentence types using /bei2/ (比) or /baa2/ (把), see Example 6 below) that do not involve more than one clause or the use of any connectives. There were a total of 11 items in this task and the children were asked to arrange three to six sentence fragments to form a syntactically correct sentence. One practice trial was given at the beginning of the task and the words of the test items were read aloud to the children. One point was given to each correctly ordered sentence.

Example 5: (1) 弟弟 younger brother / (2) 足球 football / (3) 正在玩 is playing

$$
\text { (1) (3) (2) }
$$

Example 6: 惠芬 Wai Fun (1) 志強 Chi Keung / (2) 一本圖書 a story book /

（3）借給 lend / (4) 把 Ba

Wai Fun (4) (2) (3) (1)

\section{Chinese Reading}

Chinese word reading. The Chinese Word Reading subtest of the HKT-SpLD (Ho et al., 
2000) was used to assess the children's word reading performance. The children were asked to read aloud 150 Chinese two-character words in the order of graded difficulty. The test was discontinued when the child failed to read 15 words consecutively. One point was given to each word correctly read.

Chinese sentence comprehension. This task was composed of 12 written cloze sentences with a noun, a verb, an adjective, or an adverb missing in each sentence. Children were required to choose, from four choices, the word that best completed the sentence. The participants had two practice items before doing the test ones. Majority of the words used to construct the items were familiar to Grades 1 and 2 children according to the Hong Kong Corpus of Primary School Chinese (Leung \& Lee, 2002) and appropriate difficulty levels were tested in pilot studies. One point was given for each correctly answered question.

\section{Procedures}

The tasks were given to the children in a number of sessions. The duration for each group session was around 60 minutes and that for each individual session was less than 30 minutes. Tasks that were administered in groups were Raven's standard progressive matrices, pseudocharacter meaning judgment, phonological relatedness judgment, homophone awareness, morpheme comprehension, connective usage, word order, and reading comprehension. Tasks administered individually were rapid naming of numbers, word repetition, morphological construction, oral cloze, and Chinese word reading.

Results

Descriptive Analyses 
Table 1 presents the means, standard deviations, and Cronbach's alpha coefficients of the various tasks in this study. In general, the reliability of the tasks, including those adapted from other studies and constructed by the authors, was acceptable with alpha coefficients ranged from .50 to .89 .

\{Insert Table 1 here

\section{Correlation}

Table 2 shows the partial correlations among the reading-related cognitive skills and reading measures after controlling for the effect of age and IQ in the present study. In general, most of the correlations among the measures for orthographic skills (pseudo-character meaning judgment, and phonological-relatedness judgment tasks), morphological skills (homophone awareness task, morphological construction, and morpheme comprehension tasks), and syntactic skills (oral cloze, word order, and connective usage tasks) were significant. The correlation coefficients ranged from moderate to high. However, the measures for phonological processing skills (rhyme detection, rapid number naming, and word repetition tasks) were only significantly correlated with some of the cognitive measures, with low to moderate coefficients. Most of the correlations between the reading-related cognitive skills and Chinese reading measures were significant.

\{Insert Table 2 here $\}$

\section{Hierarchical Multiple Regression}

The contribution of syntactic skills, as a composite score (computed by the average $\mathrm{z}$ scores of the three syntactic tasks), to Chinese reading comprehension performance was examined by a set of hierarchical multiple regression analyses. Table 3 summarizes the results of 
these analyses with Chinese sentence reading comprehension in Grade 2 as the dependent variable. Children's age and IQ were entered in the equation first. Then, Chinese word reading in Grade 2 was entered in Step 2, followed by reading-related cognitive measures in Grade 1, including phonological processing skills, orthographic skills, and morphological skills. Syntactic skills in Grade 1 were entered in the last step. -Sixty-eight percent of the variance in sentence reading comprehension was accounted for by all the predictors. The composite score of syntactic skills accounted for an additional variance of $4 \%$ of sentence comprehension beyond that of age, IQ, Chinese word reading, and word level cognitive skills.

To further examine the relative contributions of individual syntactic skills of the first graders to their performance of Chinese sentence comprehension in Grade 2, two of the syntactic scores were entered into the model in Step 4 and the third syntactic score in Step 5. Results showed that both oral cloze and connective usage had significant contributions to Chinese sentence comprehension in Step 5 over that of all other variables. Word order was a significant predictor of sentence reading comprehension in Step 4 but not in Step 5. This suggests that all the three syntactic skills had significant contributions to Chinese reading comprehension but oral cloze and connective usage were more important than was word order.

\{Insert Table 3 here $\}$

\section{Discussion}

To re-iterate, the aims of the present study are (a) to examine the predictors of reading comprehension in Chinese; and (b) to show the relative significance of three syntactic skills (knowledge of basic morphosyntactic structure, word order, and connective usage) in children's 
reading comprehension. The multiple regression results showed that syntactic skills in Grade 1 (especially connective usage and knowledge of morphosyntactic structure) contributed to Chinese reading comprehension a year later over and above children's age, IQ, word reading, and other word level cognitive skills.

According to Koda (2005), text comprehension consists of three subprocesses, decoding, text-information building, and situation-model construction. The present findings have reconfirmed that phonological processing skills, orthographic skills, and morphological skills are significant word-level skills for decoding, i.e., they help to extract linguistic information from print during the text comprehension process. The present findings have also identified syntactic skills as an important device to facilitate text-information building, i.e., to help integrate the ideas for comprehension.

Studies in alphabetic languages have shown that syntactic skills have significant contribution to reading beyond that of phonological processing skills (e.g., Bentin et al., 1990; Siegel \& Ryan, 1998). The present findings further show that syntactic skills is an early predictor of reading comprehension in Chinese and its significance is beyond that of word level cognitive skills (including phonological processing skills, orthographic skills, and morphological skills). Syntactic skills are therefore important text-level cognitive-linguistic skills essential for textlevel processing in languages with different characteristics. However, different syntactic skills may be differentially important for text reading in different languages.

In particular, the present findings show that understanding of morphosyntactic structure and connective usage are particularly important for reading comprehension in Chinese in early years. As mentioned earlier, the impoverishment of morphosyntactic transformation is a unique 
syntactic feature of Chinese. The present study has extended So and Siegel's (1997) findings of the significant role of the basic morphosyntactic structure knowledge from word reading to sentence comprehension in Chinese. Interpretation of word meaning and word class depends more on the sentence context for Chinese than for English. Therefore, the understanding of basic morphosyntactic structure of a sentence is an essential syntactic skill for text-level reading in Chinese.

Koda (2005) has suggested that establishing text coherence is also fundamental for successful reading comprehension, and the use of connectives is an important system to convey structural organization that express underlying relational information of text. Detailed examinations of some studies on children's reading comprehension and narrative production may further explain the significant role of connective usage to Chinese reading comprehension. In these studies, children with reading comprehension difficulties often demonstrated deficits in both structural coherence (event structure) and linguistic cohesion (the use of cohesive devices to show the semantic and logical relations between clauses and sentences) of story organization which are important to narrative production (e.g., Cain, 2003; Cain \& Oakhill, 1996; Shapiro \& Hudson, 1991). In other words, mastering the use of connectives represents children's ability in understanding and, hence, making use of logical meanings between clauses exemplified by a range of connective pairs. This in turn forms a good index of how well children are in reading to comprehend the semantics and logics of the given texts. As such, connective is an important syntactic device which children may look for in comprehension, especially given the extensive use of connectives in Chinese writings (Liu, 1999).

Word order of simple sentences, which has also contributed significantly to children's 
Chinese reading comprehension in this study, is another major syntactic device that has always been regarded as fundamental for signifying grammatical relations in Chinese (Chao, 1968). In particular, word order plays a prominent role for interpreting the structure and meaning of Chinese sentences (Gong \& Peng, 2005; Hu, 2003; Liu, 2004). As mentioned earlier, grammatical function of words in Chinese sentences is marked by their order, instead of inflection or declension in English. Mastering appropriate word order in a sentence is then essential for understanding meaning of individual words and the sentence structure and, hence, essential for text comprehension in Chinese. Nevertheless, word order did not have significant contribution to Chinese reading comprehension when connective usage and oral cloze were also controlled. This may be partly due to a considerable overlap in the nature and thus contribution of the word order and connective usage tasks $(r=.71)$. Although effort has been made to avoid using connectives in constructing items for the word order task, the two tasks nonetheless involve children to deal with both the structural and semantic elements of simple or complex sentences. In fact, how well children perform in ordering words of a simple sentence relates closely with their morphosynactic ability. Developmentally, given more complex morphosyntax and flexible word order in higher grades, we expect that word order may be more important for older children reading Chinese text. This hypothesis is being examined in our on-going projects. Regarding the importance of word order in different languages, Bates and associates (1982) reported that word order served as the primary cue in guiding thematic interpretation among speakers of rigidly ordered English, whereas speakers of loosely ordered Italian relied more on semantic cues. This leads to the suggestion that word order may be less important for Chinese speakers as Chinese word order is relatively less rigid as compared with English, and 
this was found to be the case for Chinese adults (Bates \& MacWhinney, 1989).

The above suggestion appears to be in line with the claim that Chinese text reading relies primarily on semantic-driven processes and less on syntactic processes. However, the role of syntactic processes on Chinese text comprehension has not been examined much in the past. With the present findings of the significant role of syntactic skills, we suggest that Chinese text reading relies on both processes given the intertwining nature of semantic and syntactic properties of Chinese words. As shown in Shu et al.'s (1995) study, Chinese readers showed a great tendency to draw on both morphological information (e.g., semantic radical of a Chinese character) and syntactic clues (e.g., function of a word in relation to its neighboring characters) in making sense of unknown words. They then argued that such a tendency may have to do with the semantically semitransparent nature of Chinese words. In English, for instance, words are in general morphologically transparent and the meanings of complex words (e.g., unhappiness) are more readily attainable by the meanings of its parts (e.g., un-, happy). By contrast, the meaning of a Chinese word (e.g., 開明 liberal) may not be easily determined by merely looking at its parts (e.g., the semantic radicals of the two characters 門 door and 日 sun). Mori and Nagy (1999) also demonstrated the importance of providing both kanji and contextual information in sentences on helping English-speaking college students to understand Japanese words. In other words, given the intertwining relationship of syntactic and semantic processing in Chinese, we believe that both are equally important for text comprehension in Chinese. Since the present study did not have any measures on semantics, future research may examine more adequately the relative roles of semantic and syntactic skills in Chinese text comprehension and how these may contrast with text comprehension in other languages. The third subprocess of text comprehension, 
situation-model construction (i.e., how text information is synthesized with prior knowledge) may also be examined in future studies.

\section{Conclusion}

The present study represents an endeavor to investigate the role of syntactic skills in Chinese text-level reading as related to other word level cognitive factors. Given the unique syntactic features of Chinese, a non-inflectional writing system, the significance of syntactic skills in terms of word order, knowledge of basic morphosyntactic structures, and connective usage was evident in the present study. The strong longitudinal predictive power of syntactic skills for later reading comprehension suggests that this may be a good candidate for effective reading curriculum component in Chinese. 


\section{References}

Bates, E., \& MacWhinney, B. (1989). Functionalism and the competition model. In B. MacWhinney \& E. Bates (Eds.), The cross-linguistic study of sentence processing (pp. 373). Cambridge: Cambridge University Press.

Bates, E., McNew, S., MacWhinney, B., Devescovi, A., \& Smith, S. (1982). Functional constraints on sentence processing: A cross-linguistic study. Cognition, 11, 245-299.

Bentin, S., Deutsch, A., \& Liberman, I. Y. (1990). Syntactic competence and reading ability in children. Journal of Experimental Child Psychology, 49, 147-172.

Bradley, L., \& Bryant, P. E. (1985). Rhyme and reason in reading and spelling. Ann Arbor: University of Michigan Press.

Cain, K. (2003). Text comprehension and its relation to coherence and cohesion in children's fictional narratives. British Journal of Developmental Psychology, 21, 335 - 351.

Cain, K., \& Oakhill, J. (1996). The nature of the relationship between comprehension skill an th3 ability to tell a story. British Journal of Developmental Psychology, 14, 187 - 201.

Carlisle, J. (1988). Knowledge of derivational morphology and spelling ability in fourth, sixth, and eighth graders. Applied Psycholinguistics, 9, 247 - 266.

Chao, Y. R. (1968). A grammar of spoken Chinese. Berkeley: University of California Press.

Chen, M. J., Lau, L. L., \& Yung, F. Y. (1993). Development of component skills in reading Chinese. International Journal of Psychology, 28, 481-507.

Cunningham, A. E., \& Stanovich, K. E. (1991). Tracking the unique effects of print exposure in children: Associations with vocabulary, general knowledge, and spelling. Journal of Educational Psychology, 83, 264 - 274. 
Deacon, S., \& Kirby, J. R. (2004). Morphological awareness: Just “more phonological”? The roles of morphological and phonological awareness in reading development. Applied Psycholinguistics, 25, 223 - 238.

DeFrancis, J. (1984). The Chinese Language: Fact and fantasy. Honolulu: the University of Hawai'i Press.

Denckla, M. B., \& Rudel, R. (1976). Rapid automatised naming (R. A. N.): Dyslexia differentiated from other learning disabilities. Neuropsychologia, 14, 471 - 479.

Deutsch, A., \& Bentin, S. (1996). Attention factors mediating syntactic deficiency in readingdisabled children. Journal of Experimental Child Psychology, 63, 386-415.

Fowler, A. E., \& Liberman, I. Y. (1995). The role of phonology and orthography in morphological awareness. In L. B. Feldman (Ed.), Morphological aspects of language processing. Mahwah, NJ: Erlbaum.

Gombert, J. E. (1992). Metalinguistic development. Chicago: University of Chicago Press.

Gong, S. Y., \& Peng, D. L. (2005). Advances in the researches on the development of syntactic awareness and the relationship between syntactic awareness and reading comprehension [In Chinese]. Psychological Sciences, 28, 754-756.

Gottardo, A., Stanovich, K. E., \& Siegel, L. S. (1996). The relationships between phonological sensitivity, syntactic processing, and verbal wording memory in the reading performance of third-grade children. Journal of Experimental Child Psychology, 63, 563-582.

Hakes, D. T. (1980). The development of metalinguistic abilities in children. Berlin: Springer Verlag.

Halliday, M. A. K., \& Hasan, R. (1976). Cohesion in English. London: Longman. 
Ho, C., Chan, D., Tsang, S., \& Lee, S. (2000). The Hong Kong Test of Specific Learning Difficulties in Reading and Writing. Hong Kong: Hong Kong Specific Learning Difficulties Research Team.

Ho, C. S. H., Chan, D. W. O., Lee, S. H., Tsang, S. M., \& Luan, V. H. (2004). Cognitive profiling and preliminary subtyping in Chinese developmental dyslexia. Cognition 91, 43-75.

Ho, C. S. H., Chan, D. W. O., \& Tsang, S. M. L. (2002). The cognitive profile and multipledeficit hypothesis in Chinese developmental dyslexia. Developmental Psychology, 38, $543-553$.

Ho, C. S. H., Ng, T. T., \& Ng, W. K. (2003). A "radical" approach to reading development in Chinese: the role of semantic radicals and phonetic radicals. Journal of Literacy Research, $35,849-878$.

Hu, Y. S. (2003). 現代漢語 [新版] (Modern Chinese (New Addition)) [IN Chinese]. Hong Kong: Joint Publishing.

Juel, C., L., G. P., \& Gough, P. B. (1986). Acquisition of literacy: A longitudinal study of children in first and second grade. Journal of Educational Psychology, 78, 243 - 255.

Koda, K. (2005). Insights into Second Language Reading: A Cross-linguistic Approach. Cambridge: Cambridge University Press.

Ku, Y. M., \& Anderson, R. C. (2003). Development of morphological awareness in Chinese and English. Reading \& Writing: An Interdisciplinary Journal, 16, 399 - 422.

Leung, M. T., \& Lee, A. (2002). The Hong Kong Corpus of Primary School Chinese. Paper presented at the 9th Meeting of the International Clinical.

Li, C. N., \& Thompson, S. A. (1981). Mandarin Chinese: A functional reference grammar. 
Berkely: University of California Press.

Li, W., Anderson, R. C. N., Nagy, W., \& Zhang, H. (2002). Facets of metalinguistic awareness that contribute to Chinese literacy. In W. Li, J. S. Gaffney \& J. L. Packard (Eds.), Chinese children's reading acquisition: Theoretical and pedagogical issues. Norwell, MA: Kluwer Academic Publishers.

Liberman, I. Y., Shankweiler, D., \& Liberman, A. M. (1989). The alphabetic principle and learning to read. In D. D. Shankweiler \& I. Y. Liberman (Eds.), Phonology and reading disability: Solving the reading puzzle (pp. 1-33). Ann Arbor: The University of Michigan Press.

Liu, I. M. (1999). A comparison study of the structure of thinking shown in Chinese and English sentences [IN Chinese]. Chinese Journal of Psychology, 41, 131 - 165.

Liu, X. M. (2004). 現代漢語句子生成問題研究：一個以語序為樣本的探索 (A study on Modern Chinese sentence production: an exploration into a sample of word-order) [IN Chinese]. Shanghai Shi, China: Hua dong shi fan da xue chu ban she.

McBride-Chang, C., \& Ho, C. S. H. (2005). Predictors of beginning reading in Chinese and English: A 2-year longitudinal study of Chinese kindergartens. Scientific Studies of Reading, 9, 117 - 144.

McBride-Chang, C., Shu, H., Zhou, A., Wat, C. P., \& Wagner, R. (2003). Morphological awareness uniquely predicts young children's Chinese character recognition. Journal of Educational Psychology, 95, 743-751.

Mori, Y., \& Nagy, W. (1999). Integration of information from context and word elements in interpreting novel kanji compounds. Reading Research Quarterly, 34, 80-101. 
Muter, V., Hulme, C., Snowling, M. J., \& Stevenson, J. (2004). Phonemes, rimes, vocabulary, and grammatical skills as foundations of early reading development: Evidence from a longitudinal study. Developmental Neuropsychology, 40, 665-681.

Nation, K., \& Snowling, M. J. (2000). Factors influencing syntactic awareness skills in normal readers and poor comprehenders Cambridge Journal, 21, 229-241.

Nunes, T., Bryant, P., \& Bindman, M. (1997). Morphological spelling strategies: Developmental stages and processes. Developmental Psychology, 33, 637 - 649.

Olson, R., Wise, B., Conners, F., \& Rack, J., \& Fulker, D (1989). Specific deficits in component reading and language skills: Genetic and environmental influences. Journal of Learning Disabilities, 25, 681 - 703.

Plaza, M. (2001). The interaction between phonological processing, syntactic awareness and reading: a longitudinal study from Kindergarten to Grade 1. First Language, 21, 3-24.

Plaza, M., \& Cohen, H. (2003). The interaction between phonological processing, syntactic awareness, and naming speed in the reading and spelling performance of first-grade children. Brain and Cognition, 53, 287-292.

Plaza, M., \& Cohen, H. (2004). Predictive influence of phonological processing, morphological/syntactic skill, and naming speed on spelling performance. Brain and Cognition, 55, 368-373.

Pratt, C., Tunmer, W. E., \& Bowey, J. A. (1984). Children's capacity to correct grammatical violations in sentences. Journal of Child Language, 11, 129-141.

Rack, J., Hulme, C., Snowling, M. J., \& Wightman, J. (1994). The role of phonology in young children learning to read words: the direct mapping hypothesis. Journal of Experimental 
Child Psychology, 57, 42-71.

Shankweiler, D., Crain, S., \& Brady, S. (1992). Identifying the causes of reading disability In P. B. Gough, L. C. Ehri \& R. Treiman (Eds.), Reading Acquisition (pp. 275-305). Hillsdale, NJ: Erlbaum.

Shapiro, L. R., \& Hudson, J. A. (1991). Tell me a make-believe story: Coherence and cohesion in young children's picture-elicited narratives. Developmental Psychology, 27, 960 - 974.

Share, D. L., \& Stanovich, K. E. (1995). Cognitive processes in early reading development: Accommodating individual differences into a model of acquisition. Issues in Education: Contributions from Educational Psychology 1, 1-57.

Shu, H., Anderson, R. C., \& Wu, N. (2000). Phonetic awareness: knowledge of orthographicphonology relationships in the character acquisition of Chinese children. Journal of Educational Psychology, 92, 56 -62.

Shu, H., Anderson, R. C., \& Zhang, H. C. (1995). Incidental Learning of Word Meanings while Reading: A Chinese and American Cross-cultural Study. Reading Research Quarterly, 30, $76-95$.

Shu, H., McBride-Chang, C., Wu, S., \& Liu, H. (2006). Understanding Chinese developmental dyslexia: Morphological awareness as a core cognitive construct. Journal of Educational Psychology, 98, 122 - 133.

Siegel, L. S., \& Ryan, E. B. (1988). Development of grammatical sensitivity, phonological, and short-term memory skills in normally achieving and learning disabled children. Developmental Psychology, 24, 28-37.

So, D., \& Siegel, L. S. (1997). Learning to read Chinese: Semantic, syntactic, phonological and 
working memory skills in normally achieving and poor Chinese readers Reading and Writing: An Interdisciplinary Journal, 9, 1-21.

Song, Z. G. (1992). 4-8 year-old Chinese children's judgement ability in sentence acceptability. Psychological Sciences, 5, 23-29.

Stanovich, K. E. (1988). Explaining the differences between the dyslexic and the garden-variety poor reader: The phonological-core variable-difference model. Journal of Learning Disabilities, 21, 590-612.

Stanovich, K. E. (1992). Speculations on the causes and consequences of individual differences in early reading acquisition. In P. Gough, L. Ehri \& R. Treiman (Eds.), Reading acquisition. Hillsdale, NJ: Erlbaum Associates.

Treiman, R. (1991). Phonological awareness and its roles in learning to read and spell. In D. J. Sawyer \& B. J. Fox (Eds.), Phonological awareness in reading: The evolution of current perspectives (pp. 159-189). New York: Springer-Verlag.

Tsang, K. K. S., \& Stokes, S. (2001). Syntactic awareness of Cantonese-speaking children. Journal of Child Language, 28, 703-739.

Tummer, W. E., Herriman, M. L., \& Nesdale, A. (1988). Metalinguistic abilities and beginning reading. Reading Research Quarterly, 23, 134-158.

Tummer, W. E., Nesdale, A. R., \& Wright, A. D. (1987). Syntactic awareness and reading acquisition. British Journal of Developmental Psychology, 5, 25-34.

Tunmer, W. E., \& Nesdale, A. R. (1985). Phonemic segmentation skill and beginning reading. Journal of Educational Psychology, 77, 417 - 427.

Van Kleeck, A. (1982). The emergence of linguistic awareness: A cognitive framework. Merrill- 
Palmer Quarterly, 28, 237-265.

Wang, L. (1955). 中國語法理論 (Theories of Chinese grammar) [IN Chinese]. Shanghai Shi, China: Commercial Press.

Yang, H., \& Peng, D. (1997). The learning and naming of Chinese characters of elementary school children. In H. C. Chen (Ed.), Cognitive processing of Chinese and related Asian languages (pp. 323 - 346). Hong Kong: The Chinese University of Hong Kong Press.

Zhang, Y. (1979). 康熙字典 [Kangxi Dictionary]. Beijing: The Commercial Press. 
Table 1

Reliability Coefficients, Means, Standard Deviations, and Ranges for Measures in the Present Study

Cronbach's

Variable

alpha

coefficient

Age (in months)

IQ

Rhyme Detection

Word Repetition

Mean $\quad S D \quad$ Range $\quad$ Max

Rapid Naming (in sec.)

Pseudo-character Meaning Judgment

Phonological-Relatedness Judgment

Homophone Awareness

Morphological Construction

Morpheme comprehension

Oral Cloze

Connective Usage

Word Order

Word Reading

$\begin{array}{ccc}96.27 & 3.85 & 90-108 \\ 110.27 & 14.14 & 65-135\end{array}$

Sentence Reading Comprehension

.50

7.35

2.15

$2-12$

12

.81

$45.89 \quad 14.56$

$9-68$

68

.89

23.19

5.21

$13.41-39.56$

.64

9.90

2.90

$3-16$

16

.76

$13.16 \quad 3.31$

$3-18$

18

.64

11.22

2.53

$4-15$

15

.70

15.05

4.40

$2-24$

24

.56

8.49

2.61

$1-15$

15

.59

23.38

4.03

$5-30$

30

.87

17.69

6.20

$1-27$

27

.75

8.02

2.39

$1-11$

11

$\mathrm{s}$

$100.56 \quad 19.75$

$36-144$

150

.79

$11.86 \quad 3.14$

$3-16$

16

Note. s - Standardized test. 
Table 2

Matrix of Partial Correlation Coefficients among Various Measures after Controlling for the Effect of Differences in Age and IQ

\begin{tabular}{|c|c|c|c|c|c|c|c|c|c|c|c|c|c|c|}
\hline & Variable & 1 & 2 & 3 & 4 & 5 & 6 & 7 & 8 & 9 & 10 & 11 & 12 & 13 \\
\hline 1 & Rhyme Detection & -- & & & & & & & & & & & & \\
\hline 2 & Rapid Naming & $-.15^{*}$ & -- & & & & & & & & & & & \\
\hline 4 & Pseudo-character Meaning Judgment & $.12^{*}$ & $-.21^{* *}$ & $.18^{* *}$ & -- & & & & & & & & & \\
\hline 5 & Phonological-Relatedness Judgment & $.15^{*}$ & -.01 & $.21^{* *}$ & $.23^{* *}$ & -- & & & & & & & & \\
\hline 6 & Homophone Awareness & $.16^{*}$ & $-.21^{* *}$ & $.15^{*}$ & $.33^{* *}$ & .12 & -- & & & & & & & \\
\hline 8 & Morpheme Comprehension & .09 & $-.18^{* *}$ & $.18^{* *}$ & $.31^{* *}$ & $.12^{*}$ & $.29^{* *}$ & $.33^{* *}$ & -- & & & & & \\
\hline 9 & Oral Cloze & -.01 & $-.18^{* *}$ & $.25^{* *}$ & $.28^{* *}$ & $.13^{*}$ & $.19^{* *}$ & $.40^{* *}$ & $.17^{* *}$ & -- & & & & \\
\hline 10 & Connective Usage & .08 & $-.33^{* *}$ & $.27^{* *}$ & $.46^{* *}$ & $.16^{*}$ & $.32^{* *}$ & $.46^{* *}$ & $.39^{* * *}$ & $.41^{* *}$ & -- & & & \\
\hline 11 & Word Order & .08 & $-.27^{* *}$ & $.34^{* *}$ & $.40^{* *}$ & $.15^{*}$ & $.27^{* *}$ & $.44^{* *}$ & $.44^{* *}$ & $.41^{* *}$ & $.71^{* *}$ & -- & & \\
\hline 12 & Word Reading & $.17^{* *}$ & $-.42^{* *}$ & $.27^{* *}$ & $.37^{* *}$ & $.16^{* *}$ & $.36^{* *}$ & $.36^{* *}$ & $.45^{* *}$ & $.34^{* *}$ & $.66^{* *}$ & $.61^{* *}$ & -- & \\
\hline
\end{tabular}

Note $* p<.05, * * p<.01$ 
Table 3

Summary of Hierarchical Multiple Regression Equations Predicting Sentence Reading Comprehension (Grade 2) From Reading-related Cognitive Measures (Grade 1) After Controlling for Age, IQ, and Chinese Word Reading (Grade 2)

\begin{tabular}{lccccc}
\hline & \multicolumn{5}{c}{ Reading Comprehension } \\
\hline Variable & $\Delta R^{2}$ & $R^{2}$ & $B$ & $S E B$ & $\beta$ \\
\hline Step 1 & $.17^{* * *}$ & .17 & & & \\
Age & & & .08 & .05 & .10 \\
IQ (Raven's) & & & .09 & .01 & $.41^{* * *}$
\end{tabular}

Step 2

$.43^{* * *} \quad .60$

Chinese word reading

$.11 \quad .01 \quad .69 * * *$

Step 3

$.04 * * * \quad .64$

Phonological skills (Composite score)

$.05 \quad .03 \quad .08 *$

Orthographic skills (Composite score)

$.08 \quad .06 \quad .06$

Morphological skills (Composite score)

$.22 \quad .07 \quad .17 * *$

Step 4

\begin{tabular}{|c|c|c|c|c|c|}
\hline Syntactic skills (Composite score) & $.04 * * *$ & .68 & 1.26 & .22 & $.33 * * *$ \\
\hline Step 4 & $.05 * * *$ & .69 & & & \\
\hline Connective Usage & & & .11 & .03 & $.21 * * *$ \\
\hline Oral Cloze & & & .15 & .03 & $.19 * * *$ \\
\hline Step 5 & .00 & .69 & & & \\
\hline Word Order & & & .01 & .08 & .01 \\
\hline Step 4 & $.04 * * *$ & .68 & & & \\
\hline Oral Cloze & & & .16 & .03 & $.21 * * *$ \\
\hline Word Order & & & .12 & .07 & .09 \\
\hline Step 5 & $.01 * * *$ & .69 & & & \\
\hline Connective Usage & & & .11 & .03 & $.21^{* *}$ \\
\hline Step 4 & $.03 * * *$ & .67 & & & \\
\hline Word Order & & & .06 & .08 & .04 \\
\hline Connective Usage & & & .12 & .03 & $.24 * * *$ \\
\hline Step 5 & $.02 * * *$ & .69 & & & \\
\hline Oral Cloze & & & .15 & .03 & $.19 * * *$ \\
\hline Step 4 & $.01 * *$ & .65 & & & \\
\hline Word Order & & & .19 & .07 & $.15^{* *}$ \\
\hline
\end{tabular}

$* p<.05, * * p<.01, * * * p<.001$ 